\title{
Climatic effects on blood pressure in normotensive and hypertensive subjects
}

\author{
Khalid Abdulla and Maher Taka ${ }^{1}$
}

Departments of Medicine and ${ }^{1}$ Community Medicine, College of Medicine, Mosul University, Mosul, Iraq.

\begin{abstract}
Summary: In a retrospective within-patient study, the arterial pressures of 174 normotensive and 50 hypertensive subjects in winter and summer were compared. Both systolic and diastolic pressures were higher in winter in the two groups but the differences were small and reached statistical significance only in the case of systolic pressure in normotensive subjects.
\end{abstract}

\section{Introduction}

Exposure to heat tends to decrease blood pressure $^{1-4}$ due to cutaneous vasodilatation and water and salt loss through sweating. ${ }^{3,4}$ Exposure to cold tends to increase blood pressure ${ }^{1}$ due to cutaneous vasoconstriction and increased sympathetic activity. ${ }^{4,5}$ These effects diminish after repeated or prolonged exposures as a result of acclimatisation. ${ }^{6}$

Whether climatic changes in temperature in different regions or different seasons which are usually prolonged and accompanied by protective measures in clothing and living conditions, have significant effects on the blood pressure of people in general is less certain. Smirk cited several references of authors claiming that blood pressure is lower in tropical climate and of others claiming that tropical residence has comparatively little effect. ${ }^{2}$ Blood pressure has been shown to vary seasonally in chickens, turkeys and rabbits. ${ }^{7}$

Iraq is a country with wide climatic variations between summer which is hot and dry and winter which is cold and humid (Table I). We undertook this work to see if these wide climatic variations have significant effects on blood pressure.

Hypertensive subjects may differ from normotensive subjects in their reaction to environmental factors. For example they react with a bigger rise in blood pressure in response to cold pressor test. ${ }^{8}$ They also experience a bigger rise or fall in blood pressure on increasing or decreasing sodium in the diet, the change being more pronounced in those with more severe hypertension. ${ }^{9}$ We therefore studied normotensive and hypertensive subjects separately.

Correspondence: K. Abdulla, M.R.C.P.(UK)

Accepted: 22 July 1987
Table I Average temperature and humidity during July and December for the years 1974-1982 (Nineva Meteorological Office)

\begin{tabular}{cccccc}
\hline & \multicolumn{2}{c}{ July } & & \multicolumn{2}{c}{ December } \\
\cline { 2 - 3 } \cline { 5 - 6 } Year & $\begin{array}{c}\text { Average } \\
\text { temp. } \\
\left({ }^{\circ} \mathrm{C}\right)\end{array}$ & $\begin{array}{c}\text { Average } \\
\text { humidity } \\
(\%)\end{array}$ & & $\begin{array}{c}\text { Average } \\
\text { temp. } \\
\left({ }^{\circ} \mathrm{C}\right)\end{array}$ & $\begin{array}{c}\text { Average } \\
\text { humidity } \\
(\%)\end{array}$ \\
\hline 1974 & 34.3 & 26 & & 7.5 & 86 \\
1975 & 34.3 & 21 & & 7.0 & 78 \\
1976 & 32.0 & 23 & & 10.0 & 66 \\
1977 & 34.3 & 26 & & 8.1 & 84 \\
1978 & 35.5 & 25 & & 9.5 & 85 \\
1979 & 33.8 & 20 & & 7.7 & 84 \\
1980 & 34.6 & 24 & & 8.7 & 85 \\
1981 & 35.0 & 25 & & 9.2 & 87 \\
1982 & 32.8 & 26 & & 5.6 & 83 \\
\hline
\end{tabular}

\section{Patients and methods}

The records of all patients seen by one of us (K.A.) in a private clinic from 1971 to 1977 and in the medical centre of Mosul University from 1978 to 1986, were screened. Patients who had blood pressure readings both in summer (officially defined as June 21 to September 21) and in winter (December 21 to March 21) within 3 years were identified. The limit of 3 years was to minimise ageing effects.

\section{Normotensive subjects}

Those with systolic blood pressure below $150 \mathrm{~mm} \mathrm{Hg}$ and a diastolic pressure below

(C) The Fellowship of Postgraduate Medicine, 1988 
$90 \mathrm{~mm} \mathrm{Hg}$ were classified as normotensive. Patients who at the time of the visit were suffering from acute illnesses or taking drugs likely to affect blood pressure were excluded. One hundred and seventy four patients, $61(35 \%)$ men and $113(65 \%)$ women, were thus selected for study. Their ages ranged from 12 to 80 years with a mean of 41.9 (s.d. 16.6) years. Eight patients were below the age of 20 years. The patients presented with various conditions such as musculoskeletal pains and various dyspepsias.

\section{Hypertensive subjects}

Patients with systolic blood pressures of $150 \mathrm{~mm} \mathrm{Hg}$ or above and diastolic pressures of $90 \mathrm{~mm} \mathrm{Hg}$ or above in all available readings were classified as hypertensive. Only patients who had not been on hypotensive drugs for at least one month and were not at the time of examination suffering from acute illnesses or taking drugs likely to affect blood pressure were selected. Fifty patients, $15(30 \%)$ men and $35(70 \%)$ women, fulfilled these criteria. Their ages ranged from 17 to 75 years with a mean of 45.9 (s.d. 13.9) years. They presented because of hypertension or because of other conditions as in the normotensive group.

Patients who could not be classified in one of the two groups because they had either systolic or diastolic pressure in the hypertensive range or because their blood pressure fluctuated between the normotensive and the hypertensive range at different times were not included in the study.

All blood pressure readings were casual, taken by one of us (K.A.) at the end of physical examination in the lying position, in the right arm using a standard mercury sphygmomanometer. Measurements were made by palpation first then by auscultation, the second being recorded. Phase five Korotkoff sounds was taken as the diastolic pressure. The place and time $(17.00-20.00 \mathrm{~h})$ of examination was the same in the two seasons. If a patient had more than one reading in the same season, the average was taken.

\section{Statistical analysis}

The systolic and diastolic arterial pressures of each group of patients (normotensive and hypertensive) during winter were compared with their corresponding pressures in summer using the paired $t$ test (within-patient study). The winter-summer differences in systolic and diastolic pressures encountered in the normotensive group were then compared with their corresponding values in the hypertensive group using the unpaired $t$-test.

\section{Results}

Systolic and diastolic pressures in both normotensive and hypertensive subjects were higher in winter (Table II) than in summer. The difference in systolic pressure in the normotensive subjects was statistically highly significant while that in diastolic pressure was not significant. There was no statistically significant difference in values in the hypertensive subjects.

Winter-summer differences in the hypertensive patients $(1.74 \pm 23.92 \mathrm{~mm} \mathrm{Hg}$ in systolic and $2.80 \pm$ $16.34 \mathrm{~mm} \mathrm{Hg}$ in diastolic pressures) were statistically not significantly different from those encountered in normotensive patients (3.82 \pm $16.07 \mathrm{~mm} \mathrm{Hg}$ in systolic and $0.55 \pm 11.20 \mathrm{~mm} \mathrm{Hg}$ in diastolic pressures).

\section{Discussion}

Casual blood pressure recordings are subject to various physiological and psychological influences. They also vary during the 24 hours. In this study all measurements were made in the same place, by the same person and at about the same time of the day. Those suffering from acute illnesses or taking drugs known to affect blood pressure were excluded. Furthermore casual blood pressures have been known to have a high predictive value for cardiovascular morbidity and there is no evidence that basal blood pressures are better in this regard in adults. ${ }^{10}$ We therefore felt justified to use these casual readings in comparing blood pressure in summer and winter.

Table II Paired comparison of winter and summer blood pressure in normotensive and hypertensive subjects

\begin{tabular}{|c|c|c|c|c|}
\hline $\begin{array}{c}\text { Blood } \\
\text { pressure }\end{array}$ & $\begin{array}{l}\text { Winter } \\
\text { values } \\
\text { mean } \\
( \pm \text { s.d. })\end{array}$ & $\begin{array}{c}\text { Summer } \\
\text { values } \\
\text { mean } \\
( \pm \text { s.d. })\end{array}$ & $\begin{array}{l}95 \% \text { Confidence } \\
\text { interval of the } \\
\text { mean difference }\end{array}$ & $P$ \\
\hline \multicolumn{5}{|c|}{ Normotensives: $(n=174)$} \\
\hline $\begin{array}{l}\text { Systolic } \\
\text { (mm Hg) }\end{array}$ & $\begin{array}{c}132.95^{*} \\
( \pm 20.53)\end{array}$ & $\begin{array}{c}129.17 \\
( \pm 19.48)\end{array}$ & 1.41 to 6.19 & $<0.01$ \\
\hline $\begin{array}{l}\text { Diastolic } \\
\text { (mm Hg) }\end{array}$ & $\begin{array}{r}79.88 \\
( \pm 10.35)\end{array}$ & $\begin{array}{c}79.33 \\
( \pm 9.18)\end{array}$ & -1.12 to 2.21 & NS \\
\hline \multicolumn{5}{|c|}{ Hypertensives: $(n=50)$} \\
\hline $\begin{array}{l}\text { Systolic } \\
\text { (mm Hg) }\end{array}$ & $\begin{array}{r}163.30 \\
( \pm 24.14)\end{array}$ & $\begin{array}{r}161.56 \\
( \pm 21.37)\end{array}$ & -5.09 to 8.58 & NS \\
\hline $\begin{array}{l}\text { Diastolic } \\
\text { (mm Hg) }\end{array}$ & $\begin{array}{r}101.18 \\
( \pm 15.15)\end{array}$ & $\begin{array}{r}98.38 \\
( \pm 11.04)\end{array}$ & -1.86 to 7.46 & NS \\
\hline
\end{tabular}


In a study from this centre on patients on maintenance haemodialysis, most of whom were hypertensive, systolic and diastolic blood pressure was higher in winter but the differences were also small and failed to reach statistical significance. ${ }^{11}$ Three studies from Britain are of interest. Rose ${ }^{12}$, observing 56 men with ischaemic heart disease for 3 years, found the highest blood pressures in spring and the lowest in September. Brennan et al. ${ }^{13}$ studying a population of mildly hypertensive people found a lower blood pressure in summer than in winter with a difference of $2-7 \mathrm{~mm} \mathrm{Hg}$ in systolic and $2-4 \mathrm{~mm} \mathrm{Hg}$ in diastolic pressure. Orchard et $a l^{14}$, studying a group of normotensive adolescents found that systolic pressures were lower in late autumn and diastolic lower in spring. In Japan, Hata et al. ${ }^{5}$ reported a lower blood pressure in summer than in winter in small groups of hypertensive subjects but not in normotensive subjects.

It seems from these studies and from ours, which was done in a country with wider seasonal differences in temperature and humidity (Table I), that seasonal climatic variations have a generally small effect on blood pressure. The known effects of heat and cold seem to be effectively reduced by the various protective measures in clothing and other living conditions and by physiological responses of acclimatisation. Prolonged or repeated exposures to heat can reduce the salt content of sweat considerably (up to $95 \%$ ) and decrease renal excretion of sodium and chloride, seemingly as a result of increased aldosterone secretion, so that a positive sodium balance and increased plasma volume is ultimately achieved. ${ }^{3,15-17}$ The peripheral vasodilatation produced by higher environmental temperature is compensated for by changes in other parts of the cardiovascular system in people whose sympathetic system is intact. ${ }^{12}$

\section{References}

1. Pickering, G.W. Diurnal variations in arterial pressure: the immediate responses to environmental changes. In: High Blood Pressure. J.\& A. Churchill, London, 1955, pp 24-37.

2. Smirk, F.H. Racial, geographical and environmental influences on blood pressure levels. In: High Arterial Pressure. Blackwell Scientific Publications, Oxford, 1957, pp 44-54.

3. Lee, D.H.K. Terrestrial animals in dry heat: man in the desert. In: Dill, D.B., Adolph, E.F. \& Wilber, C.G. (eds) Adaptation to the Environment. American Physiological Society, Washington, D.C., 1964, pp 551-582.
What effects such differences in blood pressure as are shown in this study may have on morbidity and mortality is difficult to predict. It is known that risks for cardiovascular disease are proportional to blood pressure level, both systolic and diastolic. ${ }^{18}$ The absolute increase in risk for a given rise in blood pressure is more at higher blood pressure levels, in older age groups, in men and more for cerebrovascular than cardiovascular disease. It is also affected by the presence or absence of other risk factors (hyperlipidaemia, cigarette smoking, carbohydrate intolerance, obesity and electrocardiographic evidence of left ventricular hypertrophy) so that for the same rise in blood pressure there is a progressively bigger increase in risk as other risk factors are added. ${ }^{10,19}$ It may be reasonable therefore to expect that the small winter-summer differences found, if they are to exert any effect on morbidity and mortality, are more likely to do so in older men with higher blood pressure and other risk factors. Morbidity and mortality from ischaemic heart disease and strokes have been known to be higher in winter and to correlate with climatic temperature. ${ }^{20-22}$

The absence of significant differences between hypertensive and normotensive subjects in their winter-summer variations of blood pressure should be interpreted cautiously because of the small number of hypertensive subjects and the fact that hypertension was mild in most of them. These considerations also prevented us from studying the different grades of hypertension separately as hypertensives of different severity may respond differently to various environmental factors, ${ }^{9}$ a point which deserves further study.

4. Keele, C.A., Neil, E. \& Joels, N., Responses to heat and cold in man. In: Samson Wright's Applied Physiology. Oxford Medical Publications, Oxford, 1982, pp 353-357.

5. Hata, T., Ogihara, T., Maruyama, A. et al., The seasonal variation of blood pressure in patients with essential hypertension. Clin Exp Hypertens [A] 1982, A4: 341-354.

6. Horvath, S.M. \& Howell, C.D., Organ systems in adaptation: the cardiovascular system. In: Dill, D.B., Adolph, E.F. \& Wilber, C.G. (eds) Adaptation to the Environment. American Physiological Society, Washington, D.C., 1964, pp 153-166. 
7. Hart, J.S. Geography and season: Mammals and birds. In: Dill, D.B., Adolph, E.F. \& Wilber, C.G. (eds) Adaptation to the Environment. American Physiological Society, Washington, D.C., 1964, pp 295-321.

8. Best, C.H. \& Taylor, N.B. The blood pressure in the human subject. In: The Physiological Basis of Medical Practice. Bailliere Tindall and Cox, London, 1955, pp 152-174.

9. Parfrey, P.S. Salt in essential hypertension. In: Sleight, P. \& Freis, E.D. (eds) Hypertension. Butterworths, London, 1982, pp 322-339.

10. Page, L.B. Epidemiology of hypertension. In: Genest, J., Kuchel, O., Hamet, P. \& Cantin, M. (eds) Hypertension. McGraw-Hill, New York, 1983, pp 683-699.

11. Abdulla, K. \& Allawi, N. Climatic effects on patients on maintenance haemodialysis. Journal of the Faculty of Medicine, Baghdad, 1985, 91-96.

12. Rose, G., Seasonal variation in blood pressure in man. Nature 1961, 189: 235.

13. Brennan, P.J., Greenberg, G., Miall, W.E. \& Thompson, S.G. Seasonal variation in arterial blood pressure. $\mathrm{Br}$ Med J 1982, 285: 919-923.

14. Orchard, T.J., Hedley, A.J. \& Mitchell, J.R.A. The distribution and associations of blood pressure in an adolescent population. $J$ Epidemiol Community Health 1982, 36: 35-42.
15. Dill, D.E., Hall, F.C. \& Edwards, H.T. Changes in composition of sweat during acclimatisation to heat. Am J Physiol 1938, 123: 412-419. Cited by Lee (Reference No. 3).

16. Streeton, D.H.P., Conn, J.W., Louis, L.H. et al. Secondary aldosteronism: metabolic and adrenocortical responses of normal men to high environmental temperatures. Metabolism 1960, 9: 1071-1092.

17. Conn, J.W. Aldosteronism in man. JAMA 1963, 183: 775-781.

18. Kannel, W.B. Incidence, prevalence and mortality of cardiovascular disease. In: Hurst, J.W. (ed) The Heart. McGraw-Hill, New York, 1982, pp 621-630.

19. Dollery, C.T. Arterial hypertension. In: Wyngaarden, J.B. \& Smith, L.H. (eds) Cecil Textbook of Medicine. W.B. Saunders, Philadelphia, 1982, pp 223-239.

20. Bull, G.M. Meteorological correlates with myocardial and cerebral infarction and respiratory disease. $\mathrm{Br} J$ Prev Soc Med 1973, 27: 108-113.

21. Blackburn, H. \& Gillum, R.F. Heart disease. In: Last, J.M. (ed) Maxcy-Rosenau Public Health and Preventive Medicine. Appleton Century Crofts, New York, 1980, pp 1168-1201.

22. Ramirez-Lassepas, M., Haus, E., Lakatua, D.J., Sackett, L. \& Swoyer, J. Seasonal (circannual) periodicity of spontaneous intracerebral haemorrhage in Minnesota. Ann Neurol 1980, 8: 539-541. 